\title{
Ecuador 1980-1990: crisis, ajuste y cambio de régimen de desarrollo
}

\section{Ecuador 1980-1990: Crisis, Adjustment, and Change of Development Regime}

\author{
Julio Oleas Montalvo \\ Instituto de Altos Estudios Nacionales, Ecuador, email: julio.oleas@iaen.edu.ec
}

\begin{abstract}
Resumen. En la década de 1980 terminó la industrialización dirigida por el Estado, comenzaron las reformas de mercado y cambió la forma de gestionar la política económica. En Ecuador los gobiernos de los presidentes Osvaldo Hurtado (19811984), León Febres Cordero (1984-1988), Rodrigo Borja (1988-1992) y la influencia del FMI promovieron este cambio adaptativo al régimen económico alentado por las emergentes doctrinas neoconservadoras de la época. Se estudian las cartas de intención remitidas al FMI y las memorias anuales del Banco Central del Ecuador, además de otras fuentes primarias. El PIB creció en promedio $2.4 \%$ anual, mientras la población lo hizo 2.6\%; la gestión de la crisis se desplazó desde la Junta Nacional de Planificación hacia el Banco Central, entidad que hizo de la devaluación monetaria su principal herramienta de política económica.
\end{abstract}

Palabras clave: enfermedad holandesa; industria petrolera; industrialización sustitutiva de importaciones.

Abstract. In the 1980s ended industrialization managed by the State, began the so called market reforms, and changed public management. This adaptive change towards the economic regime promoted by the emerging neoconservative social doctrine was fostered by presidents Oswaldo Hurtado (1981-1984), León Febres Cordero (1984-1988, Rodrigo Borja (1988-1992), and the IMF influence in the Country. The Central Bank's annual reports and the proposals to the IMF are analyzed, as well as other primary sources. The ecuadorean GDP grew 2.4 per cent annual average, while population grew 2.6 per cent. The Central Bank take the place of the Junta Nacional de Planificación in order to manage the crisis, and money devaluation became the main tool of economic policy.

Keywords: Dutch disease; petroleum industry; import sustitution industrialization.

Recibido: 15 de noviembre de 2015. Aceptado: 13 de junio de 2016.

Am. Lat. Hist. Econ., ene.-abr., 2017, pp. 210-242 | DOI: 10.18232/alhe.v24i1.724 


\section{INTRODUCCIÓN}

$\mathrm{L}$ os años ochenta del siglo $\mathrm{XX}$ han sido estudiados como un periodo de estanflación y crisis de pagos internacionales (véase cuadro 1). En esos años también culminaron, en toda la región latinoamericana, cambios similares a los iniciados en la década anterior en Chile y Argentina por las dictaduras militares de Pinochet y la Junta de Comandantes. En Ecuador, a diferencia de lo ocurrido en el Cono Sur, esta "reconstrucción radical de la sociedad civil" que terminó con las tendencias de política económica predominantes desde la década de los treinta (Bértola y Ocampo, 2012, p. 242) se produjo a la luz de la tenue democracia inaugurada en 1979. ${ }^{1}$

En esos años la región latinoamericana fue obligada a limitar su consumo interno para convertirse en exportadora neta de recursos financieros. Una vez postergada la industrialización sustitutiva de importaciones (en adelante ISI) se reasumió la especialización productiva en materias primas, según la teoría de las ventajas comparativas, y se gestionó el retroceso de los avances sociales logrados en el periodo previo. En este proceso de readaptación al capitalismo mundial, América Latina vio retroceder la producción, el consumo y la inversión, y la pobreza se expandió hasta alcanzar $41 \%$ de los hogares de la región (véase cuadro 1).

Rosemary Thorp (1998) advierte, recogiendo una observación de Osvaldo Sunkel, que

Se forzó a los países a pasar de un desequilibrio [en las cuentas fiscales] a otro: a un superávit de la balanza de pagos, con enormes costos sociales. Esto se advierte si se observa la dinámica interna que acompañó el incremento de las transferencias al exterior. El principal instrumento de transferencia interna fue la recesión, que produjo recortes del consumo, la inversión y el crecimiento [...] El resultado fue un elevadísimo costo social tanto a corto como a largo plazo. La deuda implicó también un enorme problema fiscal, agudizado por el efecto causado por la devaluación de la moneda nacional sobre el monto del endeudamiento. El problema fiscal se vio agravado por la recesión y complicado, en los casos en que el gobierno no controlaba directamente las exportaciones, por la necesidad de obtener divisas del sector privado (p. 234).

${ }^{1}$ En Ecuador la dictadura de José María Velasco Ibarra terminó el 16 de febrero de 1972, con el golpe militar liderado por el general Guillermo Rodríguez Lara. Este a su vez fue obligado a ceder el poder al Consejo Supremo de Gobierno compuesto por los generales Guillermo Durán y Luis Leoro, y por el almirante Alfredo Poveda, quienes gobernaron entre el 11 de enero de 1976 y el 10 de agosto de 1979, antes del retorno a los cuarteles. 


\section{CUADRO 1. AMÉRICA LATINA: PIB PER CÁPITA \\ E INDICADORES SOCIALES, 1980-1990}

\begin{tabular}{lccc}
\hline Indicadores sociales & 1980 & 1985 & 1990 \\
& & & \\
PIB per cápita (índice) & 100 & 92.7 & 94.1 \\
Consumo (índice) & 77 & 69.9 & 71.6 \\
Inversión (porcentaje) & 24.4 & 16.1 & 15.9 \\
Tasa de desempleo abierto (porcentaje) & 6.7 & 10.1 & 8 \\
Sector informal urbano (porcentaje) & 40.2 & 47 & 52.1 \\
Salario real de la industria (índice) & 100 & 93.1 & 86.8 \\
Salario real mínimo (índice) & 100 & 86.4 & 68.9 \\
Gasto social per cápita (índice) & 100 & 90 & 94 \\
Hogares pobres como porcentaje del total & 35 & 37 & 41 \\
\end{tabular}

Fuente: Thorp (1998).

Este proceso empezó cuando Paul Volcker, presidente de la reserva federal estadunidense, decidió controlar la inflación. Subió la tasa de interés nominal y "comenzó una larga y profunda recesión que vaciaría las fábricas y resquebrajaría los sindicatos en Estados Unidos y llevaría al borde de la insolvencia a los países deudores, iniciándose la larga era del ajuste estructural" (Harvey, 2004, p. 29). Ecuador fue parte de esta reconfiguración del capitalismo global, condicionado por su calidad recién adquirida de país petrolero.

A diferencia de lo ocurrido en Chile, Bolivia o Perú, en Ecuador esta reconfiguración ocurrió mediante ajustes menos drásticos (en cierta manera, menos ortodoxos). No se negociaron con el Fondo Monetario Internacional (en adelante FMI) y la banca internacional acuerdos de reestructuración ejemplares, como ocurrió en México o Bolivia. Los ajustes tuvieron una cadencia distinta: "[1]a política económica durante la década de los ochenta siguió un patrón de 'pare y siga', sin continuidad de estrategias, lo que como es de esperar, contribuyó a un comportamiento económico insatisfactorio [...] un tortuoso camino hacia el ajuste" (Thoumi y Grindle, 1992 , p. 6). ${ }^{2}$

${ }^{2}$ La afirmación de Thoumi y Grindle (1992) es pertinente en lo que se refiere al ritmo y cadencia del ajuste, mas no necesariamente en cuanto a lo que insinúa que, si se hubiese verificado un ajuste más riguroso y ortodoxo, los resultados alcanzados hubieran sido cualitativamente superiores. 
En todos los países de América Latina, con excepción de Colombia, el motor de esta mutación fue la deuda externa, y no el agotamiento de la ISI, como propone el pensamiento dominante. Sin embargo, en cada uno las modalidades de procesamiento y asimilación de los cambios exigidos por el nuevo orden fueron diferentes. Mientras en el Cono Sur esto ocurrió bajo dictaduras militares y con un rígido apego al monetarismo de la Escuela de Chicago, en Ecuador la democracia reasumida en 1979 y la reciente calidad de país petrolero condicionaron la asimilación y procesamiento del nuevo periodo.

En general, la modificación de la política económica se ha analizado como una reacción natural frente al desencanto producido por la ISI. Según Albert Hirschman, "[s]e esperaba que la industrialización cambiara el orden social, y todo lo que hizo fue producir manufacturas" (en Bértola y Ocampo, 2012, p. 243). De esto no se concluye, necesariamente, que para los ochenta la ISI estuviera agotada. En Ecuador los desequilibrios y las medidas de ajuste se produjeron en una sociedad fuertemente afectada por la enfermedad holandesa contraída en la década del auge petrolero. ${ }^{3}$ Inspirados en el enfoque monetario de la balanza de pagos (en adelante EMBP), los ajustes fueron ejecutados por los presidentes Osvaldo Hurtado (19811984), León Febres Cordero (1984-1988) y Rodrigo Borja (1988-1992) para corregir desequilibrios coyunturales, pero terminaron alterando en forma integral la gestión de la política económica.

Este estudio propone que la evaluación de la década de los ochenta debe considerar el punto de inflexión entre la etapa de industrialización dirigida y planificada por el Estado y las reformas del mercado, ocurrido alrededor de 1980 (Ocampo, 2008, p. 36). Con una visión más amplia, por ese año se evidenció la mutación del capitalismo mundial desde el fordismo hacia el régimen de acumulación flexible (Torre, 1987).

Para examinar los cambios en la forma de gestionar la política económica durante esta transición se analiza la información producida por el Banco Central de Ecuador (memorias anuales, boletines, estadística macroeconómica y las cartas de intención propuestas al FMI), además de otras fuentes especializadas y generales. Como punto de partida, en el acápite siguiente se esboza la estructura económica heredada del auge petrolero. A continuación se resumen las políticas de ajuste macroeconómico ejecutadas por los gobiernos de Hurtado, Febres Cordero y Borja condicionadas, como se verá, por el monitoreo del FMI y las cartas de intención propuestas

\footnotetext{
${ }^{3} \mathrm{El}$ modelo de enfermedad holandesa fue propuesto por Max W. Corden y J. Peter Neary para explicar los efectos macroeconómicos provocados por el descubrimiento y explotación de gas natural en Holanda, en la década de 1960. Véase Corden y Neary (1982, pp. 841-842). El estudio más importante de esta enfermedad sobre Ecuador es el de Torre (1987). Para un análisis más resumido, véase Naranjo (2007, pp. 67-109).
} 
por los gobiernos ecuatorianos (lo que se analiza en el cuarto apartado). El quinto capítulo contiene varias conclusiones.

\section{LA HERENCIA DEL AUGE PETROLERO}

Las vacilaciones reseñadas por Thoumi y Grindle se explican, en parte, por las rigideces macroeconómicas causadas por la enfermedad holandesa. El nulo crecimiento de la economía ecuatoriana de los años ochenta se originó en la falta de diversificación de las exportaciones, dado el optimismo generado por la extracción de petróleo, lo que a su vez acentuó la negligencia para movilizar otros recursos (Torre, 1987). Ese optimismo era comprensible, si se considera que en 1981, poco antes de estallar la crisis, de 381 pozos perforados en la zona oriental entre 1939 y 1976 menos de $17 \%$ resultaron improductivos o no comerciales (véase cuadro 2).

La negligencia destacada por Torre (1987) se proyectó en la política fiscal y en el sector externo, en el estancamiento de los volúmenes exportados, en la postergación de todo esfuerzo por incrementar ingresos fiscales no petroleros, y en la incapacidad del sistema financiero para atraer inversión privada (Torre, 1987, pp. 62-64). Los impuestos no petroleros, que habían alcanzado un máximo de 14.6\% del PIB en 1972, se redujeron a $8.8 \%$ en 1980. En la segunda mitad de la década de los setenta el inusitado incremento de los recursos petroleros no pudo evitar el déficit fiscal, que rebasó 5\% del PIB, justificado como necesario para expandir la demanda interna.

Una economía pequeña y abierta, contagiada de la enfermedad holandesa, experimenta cambios estructurales debido a la preponderancia de un producto en el sector transable. Esta condición, combinada con el tipo de cambio fijo, inhibe la expansión de otras exportaciones -por tornarlas poco competitivas- $\mathrm{y}$ favorece la producción destinada al mercado interno. Al comenzar la década de los ochenta, las exportaciones de petróleo (crudo y derivados) representaban 63.3\% del total exportado; las exportaciones tradicionales (básicamente banano, cacao y café) representaban $26.2 \%$ del total y el $10.5 \%$ restante correspondía a exportaciones no tradicionales, incluso manufacturas.

La enfermedad holandesa ha sido analizada por varios especialistas (Jácome, Larrea y Vos, 1998; Naranjo, 2006; Torre, 1987; Wunder, 2004). Naranjo (2006) sostiene que se trató de "un caso relativamente grave... porque, al ser el petróleo propiedad del gobierno, el gasto público creció a tasas superiores al producto, lo que generó fuertes déficits en la cuenta corriente de la balanza de pagos y tasas de inflación de dos dígitos, muy superiores a las internacionales y a las históricas nacionales" (p. 84). El 


\section{CUADRO 2. POZOS PERFORADOS EN EL ORIENTE}

AL 15 DE OCTUBRE DE 1981

\begin{tabular}{|c|c|c|c|c|c|}
\hline Empresa & Operación & $\begin{array}{l}\text { Pozos secos o } \\
\text { no comerciales }\end{array}$ & $\begin{array}{c}\text { Pozos } \\
\text { productivos }\end{array}$ & $\begin{array}{c}\text { Pozos en } \\
\text { perforación }\end{array}$ & $\begin{array}{c}\text { Total } \\
\text { pozos } \\
\text { perforados }\end{array}$ \\
\hline Shell & 1939-1950 & 6 & 0 & 0 & 6 \\
\hline $\begin{array}{l}\text { Texaco-Gulf } \\
\left(\text { CEPE }^{\mathrm{a}}-\mathrm{Texaco}^{\mathrm{b}}\right)\end{array}$ & 1964-1981 & 22 & 247 & 1 & 270 \\
\hline $\begin{array}{l}\text { Minas y Petróleos } \\
\text { Anglo-Superior } \\
\text { Union-Standard }\end{array}$ & 1964-1973 & 2 & 4 & 0 & 6 \\
\hline $\begin{array}{l}\text { (California) } \\
\text { Cayman }\end{array}$ & 1968-1981 & 8 & 2 & 0 & 10 \\
\hline (СЕРE-СЕРCO) & 1970-1981 & 4 & 13 & 0 & 17 \\
\hline $\mathrm{Amoco}^{\mathrm{c}}$ & 1970-1972 & 2 & 0 & 0 & 2 \\
\hline Grace & 1968-1973 & 6 & 0 & 0 & 6 \\
\hline OKC & 1970-1976 & 4 & 0 & 0 & 4 \\
\hline Shenandoa & 1968-1973 & 1 & 0 & 0 & 1 \\
\hline $\mathrm{YPF}^{\mathrm{d}}$ (CEPE-YPF) & 1975-1981 & 2 & 1 & 0 & 3 \\
\hline $\mathrm{CEPE}^{\mathrm{a}}$ & 1976-1981 & 7 & 46 & 3 & 56 \\
\hline Total & & 64 & 313 & 4 & 381 \\
\hline
\end{tabular}

${ }^{\text {a }}$ Corporación Estatal Petrolera Ecuatoriana.

b Texas Petroleum Company.

c American Oil Company.

d Yacimientos Petrolíferos Fiscales.

Fuente: Bucaram (1983).

petróleo también contribuyó al endeudamiento externo para financiar la inversión y el consumo.

El tipo de cambio fijo (25 sucres por dólar) propició la apreciación del tipo de cambio real, lo que afectó a las exportaciones tradicionales y a la producción para el mercado interno expuesta a la competencia externa. Los servicios y la construcción atrajeron casi la mitad de la población económicamente activa incorporada a la economía y para 1982, 42\% estaba empleada en ellos. En el sector agrícola el empleo disminuyó casi ocho puntos porcentuales, y en el sector industrial se incrementó en menos de uno por ciento.

El auge del petróleo convirtió al gobierno en árbitro de las rentas derivadas de su extracción. Se crearon varios subsidios al consumo de ener- 
gía y preasignaciones presupuestarias equivalentes a derechos específicos sobre esas rentas. Esto causó inflexibilidad en el gasto público; al bajar los precios del recurso, los déficits fiscales parecían inevitables (Thoumi y Grindle, 1992, p. 29). El auge petrolero también ralentizó la inversión privada y alentó la concentración de la propiedad en torno a grupos económicos con creciente capacidad para incidir en la política pública.

La política industrial gestionada por la Junta Nacional de Planificación promovió escasos encadenamientos intersectoriales. Se prefirió demandar bienes intermedios y de capital importados. En 1978 más de 50\% de los insumos intermedios usados por la manufactura provenía del exterior. El fomento industrial alentó el uso intensivo de capital y descuidó la absorción de la mano de obra redundante en otros sectores de la economía. Al comenzar la década de los ochenta a estas falencias se sumaron tres factores que bloquearon la sustitución de importaciones: las medidas tomadas por la reserva federal, la moratoria mexicana y la reducción de los precios del petróleo (Larrea, 2006, p. 88).

La bonanza se pudo mantener hasta el final de la década de los setenta gracias a términos de intercambio favorables. El precio del petróleo se incrementó de 2.8 dólares por barril en 1972 a quince dólares por barril en 1974, y en 1980 subió una vez más a 39.5 dólares por barril. Como la ISI necesitaba una sostenida demanda interna, desde 1975 hasta 1982 la absorción se mantuvo -artificialmente- en niveles superiores al PIB (véase cuadro 3). Pero el nivel de las importaciones fue sistemáticamente superior al de las exportaciones; la apreciación del tipo de cambio real, alentada por los cambios de precios relativos y por una inflación interna más alta que la internacional, fue más que suficiente para anular la ventaja otorgada por el petróleo.

En los años finales de la década petrolera, el fácil endeudamiento externo, apalancado en la extracción de petróleo, hizo innecesario promover el ahorro interno. La deuda aumentó con rapidez y en 1980 alcanzó los 3554 millones de dólares, equivalentes a 30\% del PIB. Los desembolsos de 1980 sobrepasaron los 1949 millones de dólares, equivalentes a $78 \%$ del total exportado y, cuando subieron las tasas de interés internacionales, su servicio se tornó crítico. La crisis de la deuda puso fin a la bonanza petrolera y la política social fue supeditada al cumplimiento de las obligaciones internacionales. 


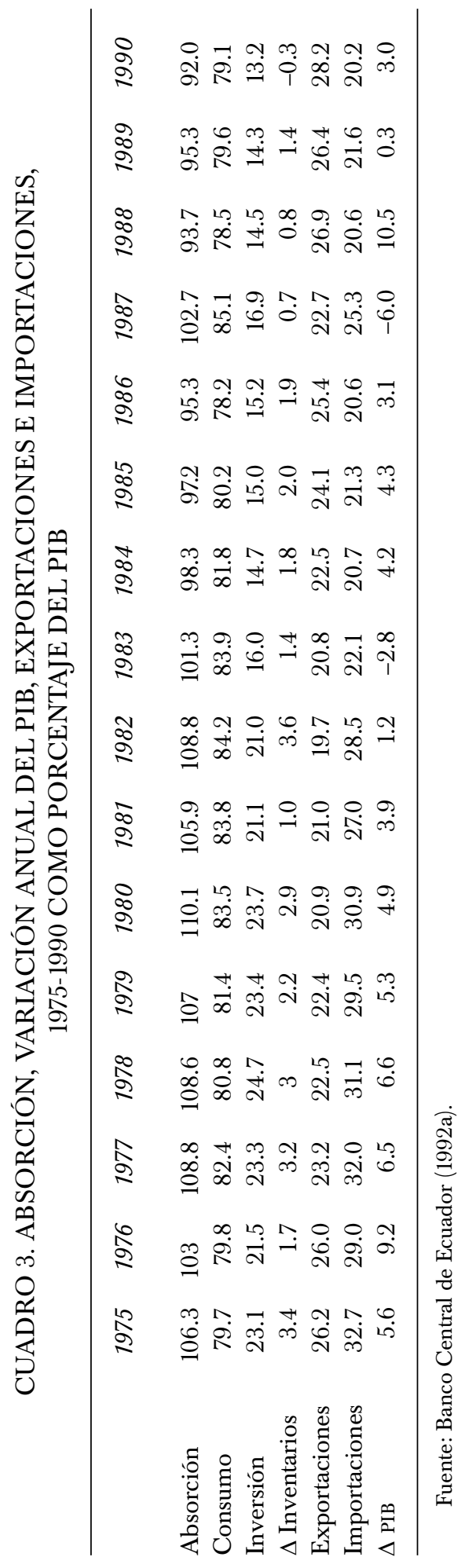




\section{EL AJUSTE MACROECONÓMICO SEGÚN EL ENFOQUE MONETARIO DE LA BALANZA DE PAGOS}

El descenso de las exportaciones, el crecimiento de las importaciones -alentado por el tipo de cambio fijo- y el peso del servicio de la deuda externa obligaron, en enero de 1982, a anunciar la priorización en la ejecución del presupuesto del Estado como primera medida para combatir los desequilibrios estructurales heredados de la década previa. Esta sección analiza el cambio de enfoque de la política económica ecuatoriana, la preponderancia de las políticas de corto plazo y la modificación del eje institucional en la que se basó esta mutación.

Según el Banco Central del Ecuador (1983), esos desequilibrios se remontarían "a los primeros ensayos de industrialización de los años 50 [...] En la década de los 70 el crecimiento de la economía continuó en base a las mismas directrices, esta vez con mayor profundidad gracias a los importantes recursos generados por las exportaciones petroleras" (p. 13). Esta crítica retrocedió dos décadas y se presentó como el producto del análisis técnico. Pero olvidó que entre 1950 y el inicio del auge petrolero (1972) la tasa anual de inflación fue, en promedio, de 3.5\%. El gerente del BCE afirmó que el "sector público se había caracterizado por conducir una política de exagerados gastos sin el correspondiente financiamiento de fuentes internas" (Banco Central de Ecuador -BCE-, 1983, p. 14), pero omitió mencionar la creciente fuga de capitales y el endeudamiento externo privado, más agresivo que el público a partir de 1977.

Los tres gobiernos de los años ochenta ejecutaron sendos paquetazos económicos para tratar de reducir el gasto público. ${ }^{4}$ En forma simultánea, en el BCE emergió una doctrina que aconsejaba corregir las distorsiones de precios relativos, disponer de un tipo de cambio competitivo, para lo cual era necesario reactivar la devaluación monetaria, anular las preferencias sectoriales; abrir la cuenta corriente y desvanecer la distinción entre sectores transables y no transables; liberar los flujos financieros internacionales, y ampliar la competitividad a todos los sectores económicos.

Era innegable que durante el auge petrolero el sector agrícola se había estancado; que, a pesar de la ISI, entre 1972 y 1980 el valor real de las importaciones de bienes y servicios había crecido a $12.5 \%$ anual; que la economía no se diversificó y seguía basada en la exportación de tres productos agrícolas y el petróleo. ${ }^{5}$ La preferencia de la ISI por los secto-

\footnotetext{
${ }^{4}$ La gente llamó de esta manera a los conjuntos de medidas de ajuste macroeconómico tomados por los gobiernos, generalmente al iniciar sus mandatos.

${ }^{5}$ En 1981 el petróleo representó $60.8 \%$ de las exportaciones y proporcionó 23\% de los ingresos fiscales.
} 
res urbanos agudizó las diferencias sociales; las protecciones arancelarias perjudicaron a los agricultores y a los consumidores, y la falta de ahorro interno fue compensada con un "agresivo endeudamiento público y privado de origen externo" (BCE, 1983, pp. 14-15).

El Banco Central de Ecuador (1983, p. 16) planteó modificar gradualmente las características del proceso productivo. La Junta Monetaria del BCE propuso emprender un amplio programa de estabilización y, a partir de 1982, asumió una posición activa que impulsó el traslado del eje de la política económica hacia la Junta Monetaria, disminuyendo al mismo tiempo la incidencia de la Junta Nacional de Planificación. Al límite de sus funciones institucionales, la Junta Monetaria comenzó a gestionar -desde una posición tecnocrática y sin suficiente legitimación política- la política económica necesaria para concretar el "programa amplio de estabilización económica". ${ }^{6}$

La burocracia que impulsaba este cambio era diferente a la que había invadido casi todos los ámbitos de la administración pública durante las dictaduras militares. ${ }^{7}$ Ganó espacio -hasta prevalecer- otra visión del desarrollo; sus adherentes usaban un vocabulario diferente. ${ }^{8}$ Su enfoque de los problemas económicos y las medidas para aplacarlos eran distintos. Consideraban que la economía era una ciencia única, apta para ser aplicada en cualquier lugar del planeta, e indispensable para corregir los desajustes provocados por la ISI. La consecuencia natural de las políticas que proponían sería el equilibrio macroeconómico para, una vez liberados los mercados de las artificiales reglas de la planificación, reiniciar el crecimiento económico, el sinónimo más preciso de desarrollo.

Sin embargo, el petrolero seguía siendo el sector más importante de la economía, pero su efecto sobre el crecimiento se diluyó, a pesar de la intensificación de su extracción, que pasó de 207000 barriles diarios en 1980 a 312000 barriles diarios en 1988 (cuadro 4), volumen de extracción

\footnotetext{
${ }^{6}$ Comenzó a ganar espacio la noción de que la política económica era un asunto técnico, que debía resolverse en forma pragmática, manteniéndola al margen de la contaminación provocada por las disputas políticas. Sin embargo de la asepsia del discurso tecnocrático, entre 1982 y 1983 presidieron la Junta Monetaria Jaime Acosta Velasco, gerente general del Banco del Pichincha, y José Correa Escobar, el principal del Grupo Corporación Financiera de Ecuador (COFIEC). El gerente general del BCE era Abelardo Pachano, quien poco después pasaría a ocupar un alto cargo ejecutivo en otro banco privado.

${ }^{7}$ La burocracia organizada alrededor de la Junta Nacional de Planificación se había preparado para enfrentar los retos de la planificación, la expansión de la infraestructura y el avance de la industrialización. Se los llamó kikuyos, en referencia al pasto tropical perenne oriundo de África Oriental (Pennisetum clandestinum), de alto potencial invasivo, que produce toxinas herbicidas capaces de matar otras plantas competidoras.

${ }^{8}$ Eran economistas familiarizados con términos como racionalización, optimización, distorsiones, consistencia, brecha, desajuste, ventajas comparativas, competitividad, agentes económicos, sistema de precios, expectativas, estabilización...
} 
que ponía en riesgo la sustentabilidad de los campos. Debido al fenómeno de El Niño, en 1983 las exportaciones de petróleo y derivados llegaron a representar $74.3 \%$ del total exportado, para luego descender a $40 \%$ en 1987 (año del terremoto que destruyó el oleoducto).

Sin opciones de corto plazo para superar la dependencia del petróleo, según los técnicos del BCE en los ochenta la evolución de la economía estuvo determinada por la crisis de la ISI y por "los efectos desencadenados por la aplicación de los programas de ajuste tendentes a corregir los principales desequilibrios macroeconómicos, especialmente en los sectores externo y fiscal" (BCE, 1990b, p. 16). La expresión más evidente de esos desequilibrios fue una inflación anual que creció de 10\% en 1981 hasta 99\% en marzo de 1989, mientras la oferta monetaria (M1) creció 32.5\% promedio anual. Este análisis sugiere una interpretación monetarista de la inflación, diferente a la de 1982, cuando todavía se hizo referencia a factores estructurales como la concentración y otras fallas prevalecientes en la mayoría de los mercados.

En los años ochenta la política económica tuvo como objetivo fundamental controlar el persistente déficit fiscal, agravado por el conflicto bélico de 1981. La inició el presidente Hurtado y la continuaron los dos gobiernos siguientes, promulgando continuamente medidas restrictivas del gasto que paralizaron la política social. Sin embargo, el ansiado superávit fiscal sólo se logró por excepción, en 1985, como consecuencia de un manejo macroeconómico muy ceñido al canon del FMI ejecutado en la primera mitad de la presidencia de Febres Cordero, y en el periodo de 19891990, cuando el presidente Borja intensificó el ajuste del gasto para frenar el descontrol heredado del gobierno anterior (véase cuadro 5). Al mismo tiempo, la inversión pública se redujo de 5.9\% del PIB en 1981 a $2.6 \%$ en 1991 (medida como formación bruta de capital fijo del sector público).

La medida de política económica más trascendental para modificar el régimen económico fue la devaluación monetaria. También la inició Hurtado, en marzo de 1982, luego de más de dos décadas de estabilidad cambiaria. En 1984 se instauró un sistema de minidevaluaciones (gradualismo que también se proyectó en subidas programadas de los precios de los combustibles y otras tarifas de servicios públicos). Con Febres Cordero se aceleró la liberalización del mercado cambiario mediante el subterfugio de cambiar las partidas arancelarias entre una lista de intervención (con tipo de cambio oficial) y otra libre (con tipo de cambio liberado), administrado por la Junta Monetaria. Al final de la década Borja restableció las minidevaluaciones, condicionándolas al control de una fuerte inflación inercial.

En palabras de Carlos J. Emanuel (1986), gerente del BCE durante el gobierno de Febres Cordero y representante del pensamiento económico emergente, 


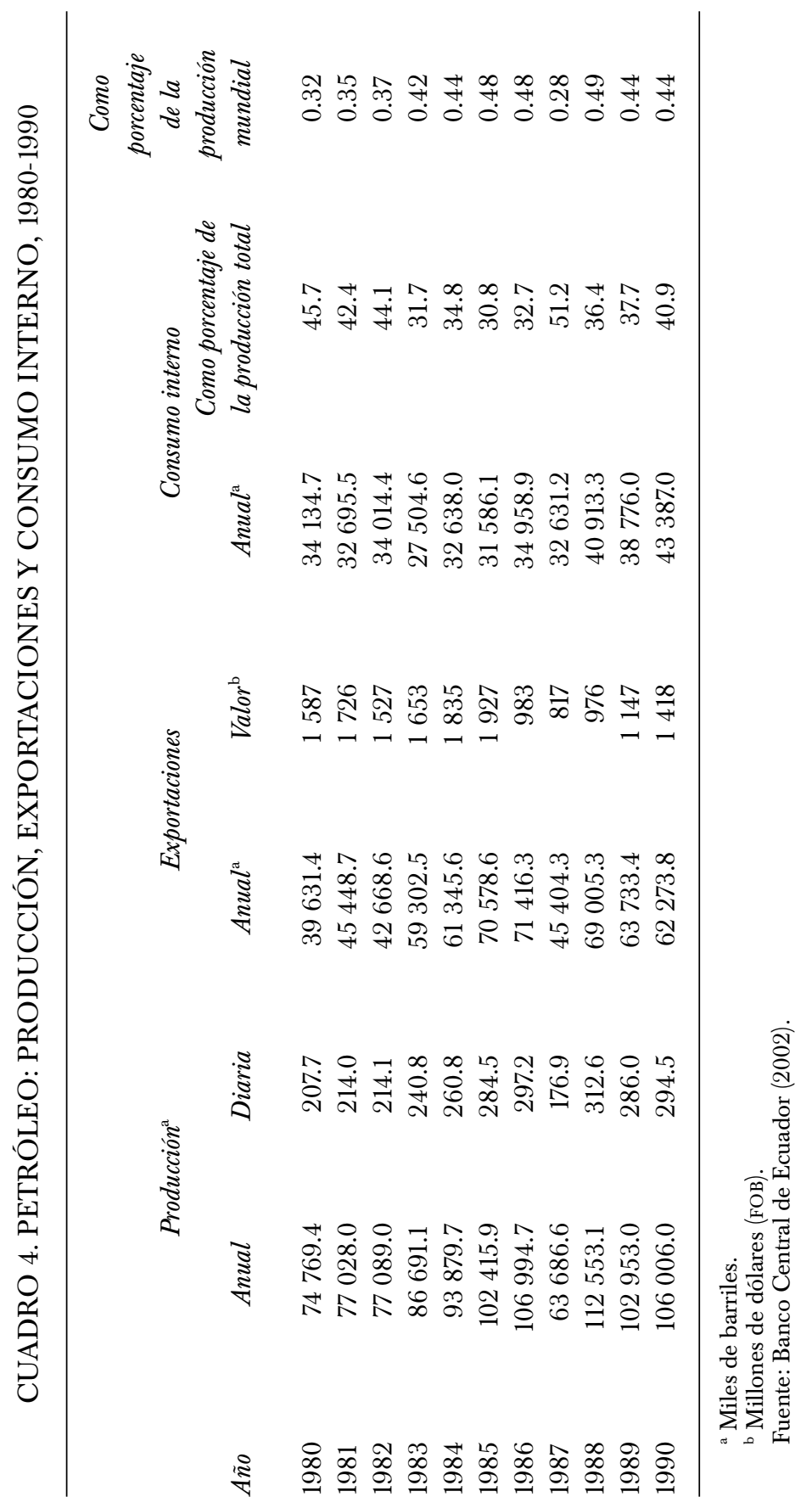




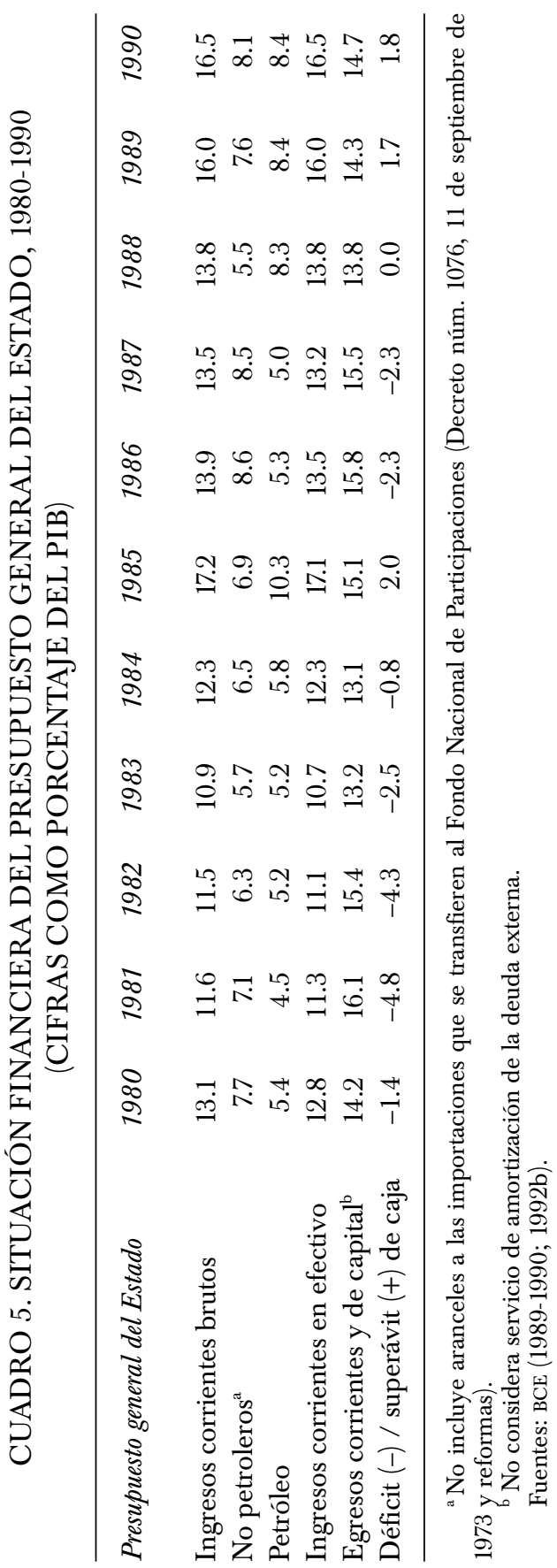


[e]n nuestros países se mantuvo [...] un tipo de cambio fijo sobrevaluado ante la inflación creciente impactando al sector externo, incrementando innecesariamente las importaciones, [...] y estimulando el endeudamiento externo. Esto ocurrió porque al mantenerse un tipo de cambio fijo [...], prácticamente se engañó a la colectividad haciéndole pensar que lo mismo daba endeudarse en moneda local o en moneda extranjera, ya que supuestamente la paridad iba a mantenerse fija ad infinitum (s. p.).

Esta radical modificación de la política cambiaria nunca pudo evitar el déficit en el sector externo, que llegó a representar 11.7\% del PIB en 1982 y 12.6\% en 1987 (cuadro 6).

En la carta de intención dirigida en julio de 1986 por Carlos J. Emanuel y Alberto Dahik, gerente del BCE y ministro de Finanzas, respectivamente, al director gerente del FMI, se destacaba que, como resultado de los ajustes cambiarios, "la paridad efectiva real del sucre a febrero de 1986 ha sido depreciada a un nivel ligeramente superior al que existía a principios de la década de 1970, antes de que se iniciare la producción y exportación del petróleo a gran escala". 9

A partir de 1987 la devaluación rebasó el ritmo necesario para corregir el engaño al que hacía referencia Emanuel, y creció más rápido que el crecimiento de los precios internos, según se puede apreciar en la séptima columna del cuadro 7, que presenta el índice de tipo de cambio real. Es decir, la aceleración de las devaluaciones perpetró otro engaño, en esta ocasión en favor de los exportadores. El cuadro 7 corrobora la severidad del ajuste cambiario: entre 1980 y 1991 el sucre se devaluó 1 472\% en el mercado oficial; $3816 \%$ en el mercado de intervención y 3 857\% en el mercado libre.

El descenso del precio del petróleo (bajó de 35.2 dólares por barril en 1980 a 12.7 dólares por barril en 1988) redujo su preponderancia en las exportaciones totales. Desde 1987 las demás exportaciones -básicamente primarias- tuvieron una ponderación que osciló alrededor de $60 \%$ de las exportaciones totales. Esto fue presentado como un logro de la política cambiaria como herramienta de diversificación de las exportaciones. Por otro lado, las devaluaciones incrementaron los márgenes de ganancia en sucres de los exportadores, incluido el gobierno, por las ventas de banano, café, cacao, camarón y petróleo. La recuperación relativa de la producción de bienes primarios para la exportación fortaleció a los grupos empresariales más tradicionales, postergados por las políticas predominantes hasta 1982.

${ }^{9}$ Emanuel, C. J. y A. Dahik (julio, 1986). Carta de intención para el director gerente del Fondo Monetario Internacional, en BCE (1990a, p. 69). 


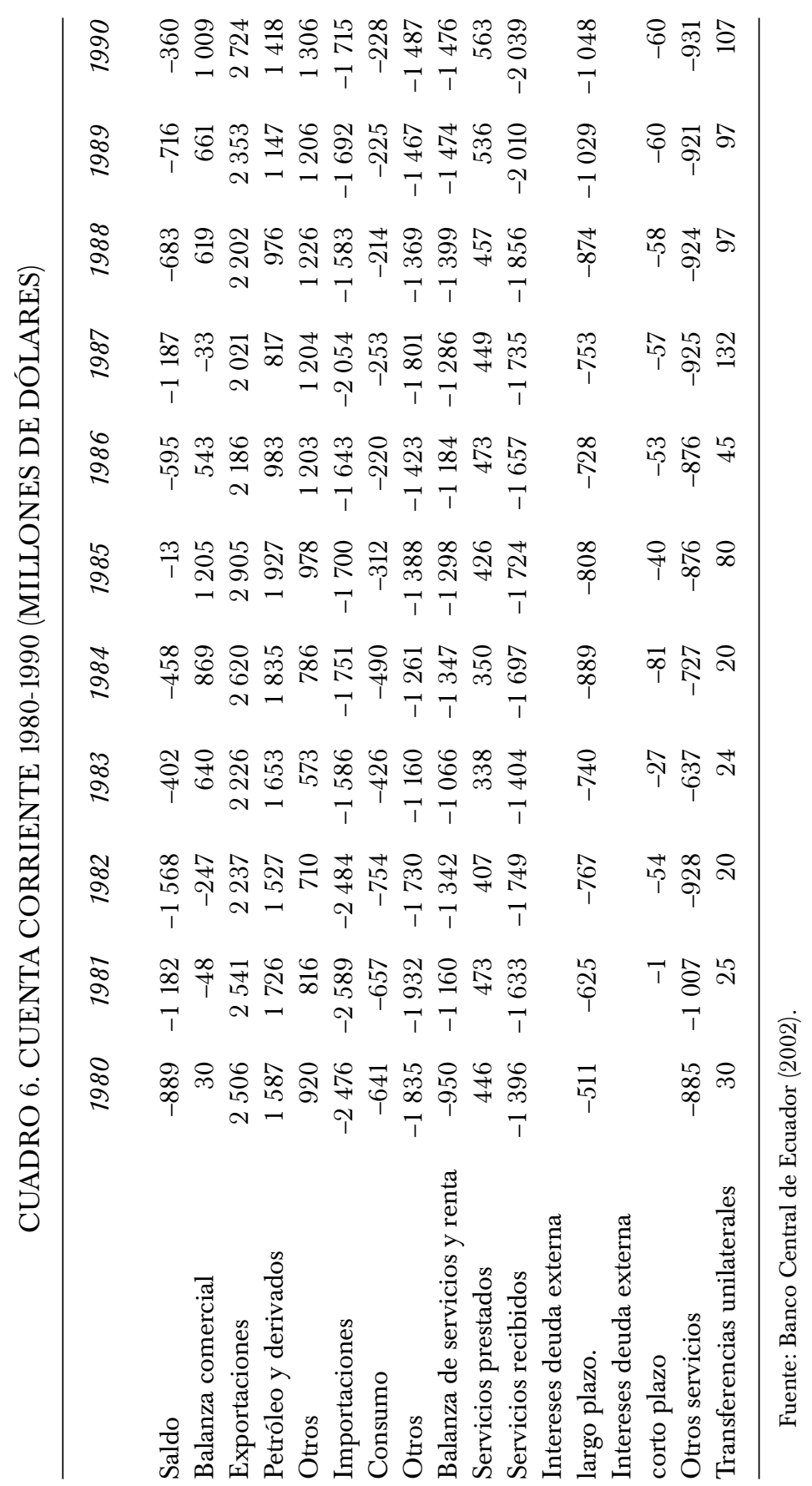




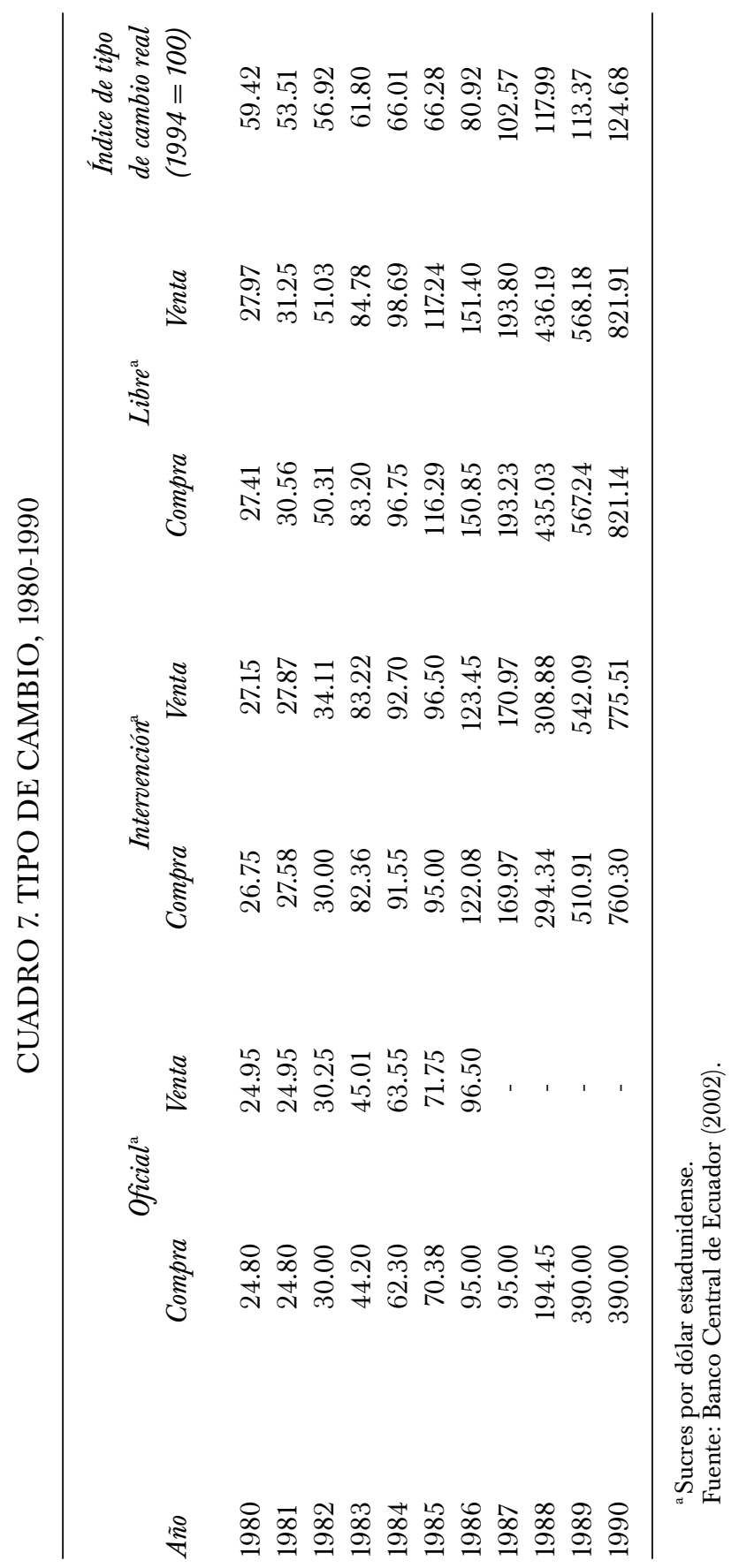


Ajustes similares se habían realizado antes en primer lugar en Chile, luego en Argentina y más tarde en Centroamérica y en la región andina. $\mathrm{Su}$ matriz teórica es el enfoque monetario de la balanza de pagos, que propone restringir el gasto fiscal para controlar el -supuesto- exceso de demanda en la economía (véase recuadro 1, anexo).

La anulación de la planificación y las políticas de industrialización duró más de una década. Los desastres naturales (El Niño, 1982-1983; terremoto, marzo de 1987) y el descenso de los precios internacionales del petróleo en 1987 intensificaron las dificultades de este tortuoso camino hacia el ajuste. Las rigideces de la enfermedad holandesa y condiciones internacionales adversas hicieron que este tránsito hacia la nueva época sea complicado, intermitente y adaptado a los intereses de los grupos que accedieron al poder sobre la base de la legitimación electoral. Cada uno de ellos gestionó su programa de ajuste macroeconómico. Pero, vistos en conjunto, todos ellos realizaron sendos avances hacia el nuevo régimen.

\section{CARTAS DE INTENCIÓN Y DEUDA EXTERNA}

El enfoque monetario de la balanza de pagos es funcional al pago de la deuda externa. Un sector público que no recurre a la monetización de sus déficits presupuestarios -es decir que se mantiene en equilibrio- contribuye a frenar el crecimiento de los precios y garantiza más recursos para atender las cuentas del pasivo de la balanza de pagos. Desencadenada la crisis, en agosto de 1982, los acreedores externos exigieron recuperar los equilibrios macroeconómicos para reanudar los pagos. Alegaron que se trataba de un evento coyuntural pero, en los hechos, en el transcurso de la década las políticas de ajuste macroeconómico anularon a las políticas de industrialización. La deuda externa también sirvió de mecanismo financiero para interrumpir la ISI, pues obligó a los países latinoamericanos a desmantelar la protección a sus industrias, a disminuir la participación del Estado en la economía, y a reducir la inversión y el gasto social para asegurar el pago de las obligaciones externas (Roddick, 1990, p. 38).

$\mathrm{Al}$ declarar la moratoria unilateral de su deuda externa, México puso en riesgo financiero al menos a uno de los grandes bancos estadunidenses. Según la legislación de Estados Unidos, los préstamos cuyos intereses no se cancelaban en 90 días debían declararse legalmente inactivos y tras 180 días de mora los bancos no podían acreditar como activo el valor total de esa deuda. El presidente Reagan impidió que los bancos estadunidenses incurrieran en insolvencia, dada su imprudente exposición en América Latina provocada por sus propias políticas (contracción monetaria, subida de los intereses y reducción de los precios internacionales de las materias 
primas): antes de 90 días, el gobierno de Estados Unidos y el Bank of International Settlements concedieron préstamos a los países insolventes con deudas de magnitud suficiente como para poner en aprietos a los bancos acreedores, asegurando el cumplimiento de sus amortizaciones, hasta negociar los nuevos acuerdos de reprogramación financiera.

El FMI promovió los ajustes macroeconómicos de los países deudores, asegurando las futuras amortizaciones de intereses. En esencia, esto se logró transformando los recursos para consumo interno en exportaciones con las cuales generar excedentes externos. "Los nuevos préstamos y la reprogramación de los antiguos se hicieron depender de la aceptación de las condiciones del FMI" (Roddick, 1990, p. 76).

Si se considera que entre 1982 y 1983 se revirtió el déficit comercial de la región, el FMI intervino con gran éxito en al menos catorce renegociaciones. A partir de entonces, con el respaldo del gobierno estadunidense y el aval del FMI y del Banco Mundial, los países deudores fueron obligados a exportar cada vez más, a menores precios, a mercados francamente proteccionistas. Los organismos multilaterales recomendaron promover las exportaciones, aceptar los precios del mercado y, con esos ingresos, honrar sus deudas. Los ajustes en los países deudores hicieron que la producción para el consumo se reconstituyera en producción para la exportación; comenzaron a competir entre ellos, evitando que los bienes primarios subieran de precio en los mercados internacionales.

La deuda externa ecuatoriana representaba una pequeña porción de la deuda latinoamericana, lo que redujo la capacidad de negociación del país. ${ }^{10}$ En 1981 -antes de la moratoria mexicana- el saldo de la deuda externa pública creció $25.1 \%$ y el de la privada $29.5 \%$, no se registraron atrasos por pago de intereses y los desembolsos recibidos, de 2767.8 millones de dólares, fueron los más altos de la década, al igual que las amortizaciones de capital y el servicio de intereses, que llegaron a 2138.7 millones de dólares. En las vísperas de la crisis, el endeudamiento ecuatoriano continuaba a toda vela.

En 1982, con ingresos por exportaciones de petróleo inferiores a los pagos de intereses y capital de la deuda, y suspendidos los flujos de capitales frescos por el default mexicano, la crisis se instaló en la economía ecuatoriana. ${ }^{11}$

${ }^{10}$ En 1987 Ecuador adeudaba 2.3\% del total adeudado por América Latina y el Caribe. Véase Roddick (1990, p. 38).

${ }^{11}$ En 1982 la exportación de petróleo produjo 1388 millones de dólares y la de derivados otros 136000000 de dólares. La suma de estos dos rubros representó 68\% de las exportaciones totales, mientras el servicio de la deuda externa de ese año (amortizaciones de capital más pago de intereses) llegó a representar $88.9 \%$ de las exportaciones totales. 
[P]ara una economía y un sector en el que su situación era típica del resultado de diez años de enfermedad holandesa y con una industria no competitiva, la crisis de la deuda que se desencadenó hacia finales de 1982 abrió un periodo de difícil ajuste, por el hecho de la inadaptación de la economía a las condiciones que prevalecieron en los años siguientes (Varea, 1993, p. 153).

El presidente Hurtado inició negociaciones concretadas en la primera carta de intención acordada en esa década (BCE, 1990a, pp. 33-41). Se la dirigió a Jacques de Larosiere, director gerente del FMI, solicitando un crédito stand-by por 157700000 derechos especiales de giro (DEG), a un año plazo. Se destacaron los avances logrados con el Programa de Estabilización Económica y Social que comprendían aspectos fiscales, comerciales, monetarios y de deuda externa. ${ }^{12}$ Este primer ajuste buscó equilibrar las cuentas fiscales y externas a base de continuas devaluaciones y de contracciones de efecto inmediato en la demanda interna, como en general destacarían todas las cartas de intención acordadas en esa década. En 1983 el gobierno ecuatoriano debía comprometerse a cumplir varias metas: reducir el déficit del sector público a 4\% del PIB, controlar los ajustes salariales, ajustar a niveles reales las tarifas de los servicios y bienes no transables, ajustar el tipo de cambio para estimular la competitividad y reducir las importaciones de bienes no esenciales. Pero también debía eliminar las prohibiciones a las importaciones implementadas en 1982. La política monetaria se comprometía a expandir en $25 \%$ el crédito al sector privado y a continuar con las elevaciones de las tasas de interés acelerando esa tendencia hasta encontrar niveles reales (BCE, 1990a, pp. 33-41). ${ }^{13}$

Las autoridades resaltaron el acuerdo con los acreedores externos, cuya negociación había comenzado en agosto de 1982 y concluido el 11 de enero de $1983 .{ }^{14}$ Una vez negociado el acuerdo stand-by, en octubre de 1983 se firmaron cuatro convenios. ${ }^{15}$ En resumen, se renegociaron 2023.4

${ }^{12}$ En este contexto se utiliza la palabra avance para significar la progresiva tendencia de las autoridades económicas de los gobiernos ecuatorianos a aplicar el enfoque monetario de la balanza de pagos como eje de las políticas de ajuste implementadas en el transcurso de esa década.

${ }^{13}$ Es importante notar que en esa primera carta las autoridades económicas todavía emplearon términos como no transables o bienes no esenciales, propios de las políticas de la ISI, que se tornarían obsoletos en el transcurso de la década.

${ }^{14} \mathrm{Al}$ principio de la década, primero se negociaba con los bancos comerciales y luego con el FMI, que debía verificar la eficacia y pertinencia del ajuste iniciado.

${ }_{15}$ De refinanciamiento de las deudas del sector público y del sector privado; de préstamo por 431000000 de dólares, y de facilidad comercial. El primero reestructuró a siete años plazo con uno de gracia 994000000 de dólares, de los cuales $70 \%$ constituían obligaciones de corto plazo, con intereses de 2.25 y $2.125 \%$ sobre las tasas Libor y Prime, respectivamente. El segundo abarcó un total de 976200000 dólares, de los cuales al menos 80\% eran obligaciones de corto plazo. La facilidad de comercio se concretó como una línea de crédito con la banca privada internacional por 750000000 de dólares, utilizables hasta el 31 de diciembre de 1984, para no paralizar el co- 
millones de dólares, incluidos 53200000 dólares adeudados al Club de París, posponiendo el pago de 2000 millones de dólares por intereses y amortizaciones vencidos -o de inminente vencimiento- y contratando créditos frescos para financiar un déficit en cuenta corriente acumulado entre 1982 y 1984 cercano a los 2500 millones de dólares.

El 19 de abril de 1984 se propuso una nueva carta de intención en la que se actualizaron los compromisos (BCE, 1990a, pp. 43-50). Los avances del Programa de Estabilización de 1982 presentados a De Larosiere eran muy positivos, desde la visión del ajuste: reducciones del déficit global del sector público a $0.5 \%$ del PIB y del déficit en cuenta corriente a $1.6 \%$ del PIB, incrementos graduales de los precios de los derivados del petróleo y de las tarifas eléctricas, más recursos petroleros captados por el gobierno (lo que garantizaba el pago de la deuda externa), más operaciones de comercio exterior transadas en el mercado libre de cambios, devaluaciones graduales y dos ajustes de las tasas de interés; el pago de $84 \%$ de los atrasos de la deuda externa, la renegociación de las deudas pública y privada, el acuerdo con el Club de París y el apego a las condiciones emanadas del convenio stand-by perfeccionado en octubre de 1983.

En esta carta el FMI condicionó la decisión del gobierno de hacerse cargo de la deuda externa privada al cobro (al sector privado) de comisiones suficientemente elevadas para cubrir las pérdidas cambiarias que pudiera ocasionar la sucretización de esos pasivos. El mayor riesgo que presentaba esa operación de rescate era el futuro diferencial cambiario, entre el tipo de cambio al que se realizaban las sucretizaciones y el tipo de cambio efectivo que tendría que asumir el nuevo deudor: el BCE. La mayor parte de las operaciones de sucretización se dio en 1984, denominándolas crédito de estabilización (cuadro 8).

En las cartas de intención de marzo de 1983 y de abril de 1984 el gobierno de Hurtado aceptó condicionar las políticas cambiaria y comercial que pudiera tomar (BCE, 1990a, pp. 33-50). Se comprometió a eliminar los atrasos de pagos de la deuda externa antes de recibir nuevos desembolsos, a realizar consultas periódicas y a preguntar al FMI cualquier cambio de política económica, antes de ponerlo en vigencia. Así, en la primera mitad de la década las cartas de intención ya condicionaron la política económica interna a la aprobación de ese organismo multilateral.

Esta relación era la que convenía a los acreedores: "El vicepresidente del Royal Bank of Canada definió la tarea del FMI para que actúe 'a la par como acreedor y como factor disciplinario, y eso es lo que a nosotros [a los acreedores] nos gusta'. El FMI, tal vez como ninguna otra institución, pue-

mercio exterior y el préstamo de 431000000 de dólares, para mejorar la situación de la balanza de pagos, se pactó con un periodo de gracia, hasta el primer trimestre de 1985. 


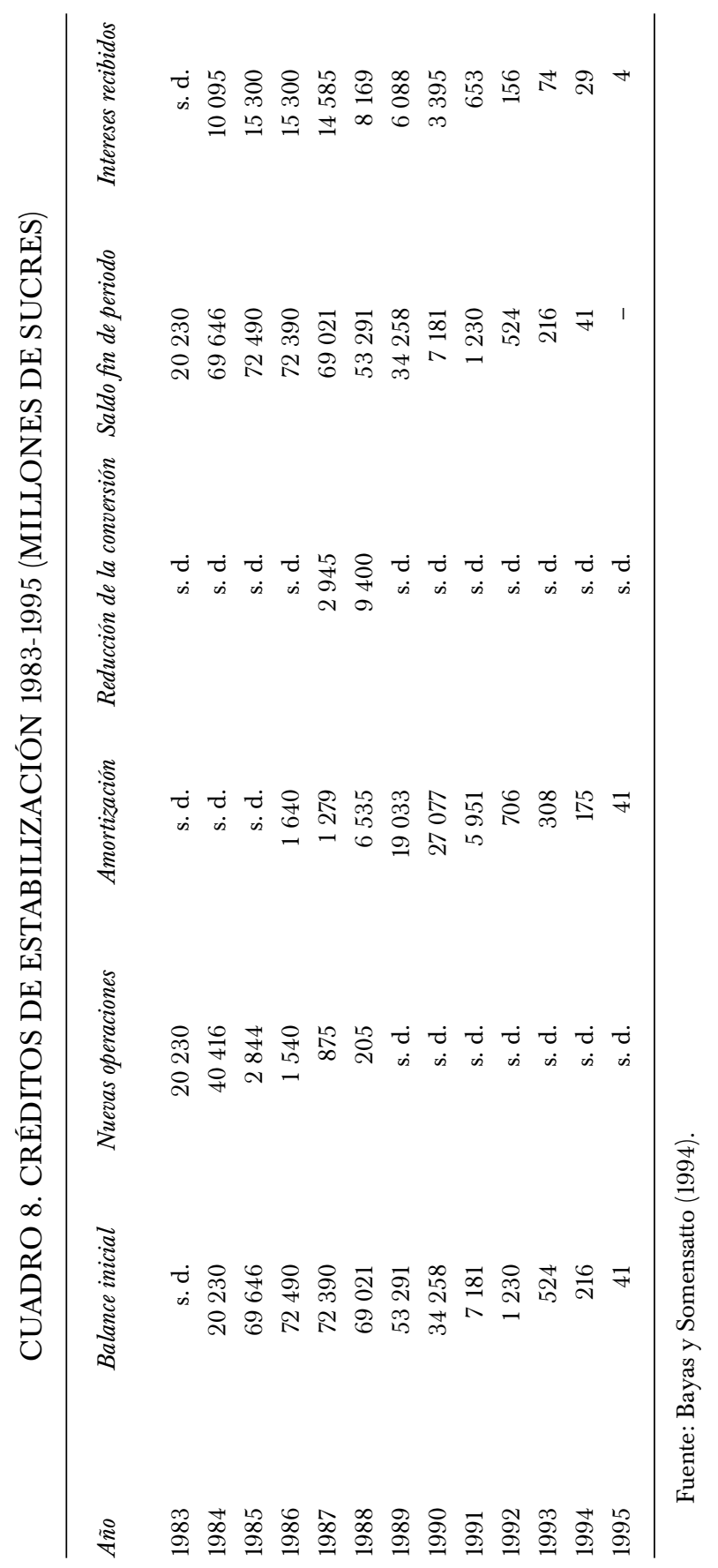


de imponer condiciones sobre los préstamos y esto asegura que los países deudores se amarren el cinturón" (Acosta, 1994, p. 234).

El equipo económico de Febres Cordero concluyó una nueva renegociación con el FMI en diciembre de 1984. Se reestructuraron vencimientos por 4500 millones de dólares de capital (entre 1985 y 1989), incluida la deuda del sector privado asumida por el BCE, y los vencimientos del crédito y la facilidad comercial contratados por el gobierno anterior. El descenso de las tasas Libor y Prime facilitó acordar tasas de interés menores y un plazo de pago a doce años, y se postergaron los desembolsos del capital hasta marzo de 1988. Los negociadores destacaron el incremento de $75 \%$ en promedio de los precios internos de los derivados del petróleo, el déficit en cuenta corriente de $2 \%$ del PIB, la liberalización de buena parte de las operaciones de comercio exterior y la eliminación de la mayoría de las prohibiciones a las importaciones decretadas en 1982 (BCE, 1990a, pp. 51-61). Para conseguir un nuevo crédito stand-by por 105500000 dólares se obligaron a cumplir metas similares a las comprometidas por el equipo de Hurtado: superávit fiscal de 3\% del PIB; reducción del gasto corriente y aumento del gasto de capital a 2.9\% del PIB; ajustes salariales indexados a la tasa de inflación futura; nuevos ajustes de los precios de los derivados del petróleo y política de precios reales para bienes y servicios públicos. Se pactó expandir en $24 \%$ el crédito bancario para el sector privado, limitar el crédito del BCE al sector público, liberar la tasa de interés y mantenerla en niveles reales positivos. Se prometió no incurrir en nuevos atrasos y pagar $60 \%$ de los ya cometidos. En el comercio exterior el compromiso se limitó a un escueto ofrecimiento de mantener la tendencia a abrir la economía (BCE, 1990, pp. 51-61).

El FMI concedió un nuevo stand-by, el de marzo de 1985, dos meses después de presentada la solicitud, confirmando la afinidad del gobierno con la visión del ajuste promovido por los organismos multilaterales. Sin embargo, ni esta afinidad, ni la visita de Febres Cordero a Washington (marzo de 1985), ni un nuevo acuerdo con el Club de París (24 de abril de 1985) aceleraron las renegociaciones con el comité de acreedores, que sólo se concretaron el 20 de diciembre de $1985 .^{16}$ En esta ocasión se renegociaron 5200 millones de dólares, de los cuales 2500 millones correspondían a deuda pública, 1400 millones a deuda privada, 600000000 a nuevos recursos y 700000000 a una línea de crédito comercial. ${ }^{17}$ La amortización refinanciada de la deuda privada equivalió a 95\% del total de esa deuda, reduciéndola

${ }^{16}$ Poco antes, en octubre de 1985, en la reunión anual del FMI celebrada en Seúl, el secretario del Tesoro estadunidense James Baker había anunciado el plan que llevaría su apellido y, dos meses más tarde, los voceros del gobierno se jactaron de que Ecuador y Argentina serían los primeros países latinoamericanos calificados para acceder al Plan Baker, algo que nunca sucedió.

${ }^{17}$ Estas cifras fueron difundidas por el BCE en su Memoria anual de 1985 y difieren de las que se han consolidado para realizar el análisis de este estudio. 
de 1628.5 millones de dólares (diciembre de 1982) a 155300 000. Con esta operación la deuda pública llegó a 8110.7 millones de dólares.

Entre 1979 y 1982 el sector privado había recibido desembolsos externos por 3480.1 millones de dólares y pagado 3044 millones de dólares (amortizaciones e intereses). Sin embargo, las condiciones financieras provocaron una acumulación de deuda de 1082 millones de dólares, con lo que el saldo de la deuda externa privada creció hasta 1628.5 millones de dólares. Este saldo representó en 1982 una cuarta parte de la deuda externa total del país. Este juego financiero sólo podía continuar si se recibía dinero fresco, lo que se tornó imposible luego de la moratoria mexicana. En esta situación, en junio de 1983 el gobierno de Hurtado dio paso a la primera etapa de la sucretización de las deudas privadas. ${ }^{18}$

El beneficio recibido por los empresarios se justificó como protección de las fuentes de empleo. La mayoría de los beneficiarios de la sucretización de 1983 fueron grupos económicos con más de una empresa. Todos los grupos económicos con deudas superiores a 10000000 de dólares estaban domiciliados en Guayaquil, con excepción de la empresa constructora de la central hidroeléctrica de Agoyán y de Indupalma, empresa cultivadora de palma africana en el noroccidente y en el nororiente. El grupo COFIEC, con una deuda superior a 110000000 de dólares, representaba $22.2 \%$ del total sucretizado en 1983. "Como se recuerda, el presidente de COFIEC fue presidente de la Junta Monetaria al dictarse la sucretización de la deuda privada" (Fierro, 1991, p. 559). La mayor parte eran empresas dedicadas a actividades especulativas (financieras, comerciales e inmobiliarias) y los primeros beneficiarios de la sucretización fueron "el propio capital extranjero y los grupos de poder económico ecuatorianos, constituidos por un minúsculo número de familias". ${ }^{19}$

La segunda etapa de la sucretización se cumplió en los primeros meses de la presidencia de Febres Cordero y consistió en la extensión de los plazos y congelamiento del tipo de cambio, lo que habría generado "una pérdida cambiaria para el Banco Central que actualmente bordea los 600

\footnotetext{
${ }^{18}$ Durante toda la década de 1980 el BCE no proporcionó información sobre las operaciones de sucretización. Recién en la Memoria anual de 1989 (вCE, 1989) se realizó un pormenorizado recuento de desembolsos, amortizaciones e intereses para el periodo 1985-1989, es decir cuando lo fundamental del proceso ya se había consumado. Mientras que en 80 años de información estadística (Series Estadísticas Históricas) se indica que en 1983 se sucretizaron 490000000 de dólares, Luis Fierro (1991, pp. 562-565) cuantificó 630800000 dólares, correspondientes a los 100 principales deudores privados, de un total general de 1355.6 millones de dólares de deuda externa privada. La información del BCE indica que en los cuatro años que duró el proceso de sucretización los saldos de la deuda privada se redujeron en un total de 1543 millones de dólares. Los valores sucretizados se distribuían en unas 40000 operaciones de 15000 clientes.

${ }^{19}$ Tafur, M. (1986). Los beneficiarios de la sucretización, Revista Orientación, 8, 47, citado por Fierro (1991, p. 559).
} 
mil millones de sucres" (Fierro, 1991, p. 560). De la evidencia investigada se puede colegir que en un principio el FMI se habría opuesto a que el BCE asumiera todo el riesgo cambiario, pero al final del día esa entidad era garante de los acreedores externos y le importaba menos quién pudiera asumir las pérdidas derivadas del riesgo cambiario. Esas pérdidas se escondieron en una cuenta del activo diferido del balance del BCE que al final de la década ya no pudo ocultarse, debido al perjuicio irrogado a esa entidad y a las presiones inflacionarias que generaba.

Las cartas de intención siempre estuvieron precedidas por las visitas de las misiones del FMI para negociar políticas y metas macroeconómicas. Cada carta ya implicaba un acuerdo previo que debía someterse a la aceptación formal del organismo multilateral. El 14 de julio de 1986, urgido por el descenso de los precios del petróleo, el gobierno remitió a De Larosiere una nueva carta de intención pidiendo otro stand-by por 75400000 DEG (BCE, 1990a, pp. 63-74). Luego del terremoto de marzo de 1987 se insistió con una nueva carta de intención (3 de diciembre de 1987) dirigida a Michael Camdessus, en la que se reiteró el pedido del stand-by (BCE, 1990a, pp. 75-82). A pocos meses del fin del gobierno, el equipo económico ofreció al FMI reducir el déficit del sector público a 1.5\% del PIB y también el déficit de cuenta corriente, sin proponer una cifra concreta. Hasta donde se conoce, esta carta no fue considerada siquiera por el FMI. ${ }^{20}$ Las autorida- $^{-}$ des socialcristianas ofrecieron informar mensualmente sobre la ejecución del presupuesto del gobierno central y el gasto de capital realizado por las dos empresas más importantes del país, Corporación Estatal Petrolera Ecuatoriana e Instituto Ecuatoriano de Electrificación; abstenerse de restringir importaciones por medio de autorizaciones previas y unificar el mercado de cambios, además del compromiso de realizar consultas previas a la adopción de cualquier medida adicional. ${ }^{21}$

El gobierno de Borja tardó un año en preparar su primera carta de intención, buscando un crédito stand-by por 109900000 DEG (BCE, 1990a, pp. 41-94). En ella evidenció los profundos desequilibrios fiscal y externo, así como la grave situación inflacionaria heredados del gobierno socialcristiano, y mencionó -por primera vez en un documento oficial en esa década- el alto desempleo prevaleciente en la economía ecuatoriana. También destacó los logros del Plan de Emergencia Económica Nacional iniciado en septiembre de 1988. En general, la línea del ajuste ofrecía los mismos

${ }^{20}$ Tafur, M. (1986). Los beneficiarios de la sucretización, Revista Orientación, 8, 75-82, citado por Fierro (1991, p. 559). La diferencia entre el ofrecimiento de las autoridades socialcristianas y la realidad queda evidenciada por el hecho de que en agosto de 1988 la reserva internacional arrojó una cifra negativa de 330000000 de dólares.

${ }^{21} \mathrm{El}$ mes en que se preparó esa carta (diciembre, 1987) la reserva internacional ya era de 151000000 de dólares. 
hitos de las cinco cartas anteriores, pero en esta ocasión se propuso reducir el capital de la deuda, para lo cual se ofreció destinar una cuarta parte del convenio stand-by y, mientras tanto, pagar un tercio de los vencimientos de 1989 (BCE, 1990a, pp. 83-94).

Los pagos del servicio de la deuda, suspendidos antes del terremoto de 1987, en enero de ese año, se reiniciaron en julio de 1989, pero limitándolos a un tercio de los vencimientos. Con el Club de París se refinanciaron los vencimientos correspondientes a 1989 y 1990. En febrero de 1990 se remitió una nueva carta de intención que exhibía resultados realmente promisorios, según los criterios de las entidades multilaterales: el déficit fiscal del sector público no financiero se había reducido a $2.2 \%$ del PIB y el déficit de cuenta corriente a $4.5 \%$ del PIB; las reservas internacionales se recuperaron hasta alcanzar los 205000000 de dólares (BCE, 1990a, pp. 95-105). Estas cifras superaban las metas ofrecidas en agosto de 1989, pero la tasa de inflación se mantuvo sobre $52 \%$ anual. No obstante el débito arbitrario de una cuenta del Estado ecuatoriano, por 80000000 de dólares, ejecutado por el Citibank en abril de 1989, se propuso una renegociación amplia, que incluía un programa de nuevas reformas, de tipo estructural, sincronizado con la estrategia de reducción de la deuda externa (BCE, 1990a, pp. 95-105).

Entre 1989 y 1991 Ecuador recibió desembolsos por 3301 millones de dólares y contabilizó amortizaciones por 3304 millones. En realidad sólo se pagaron 2239 millones, lo que provocó una acumulación de atrasos por intereses de 5815 millones de dólares. El gobierno de Borja nunca pudo renegociar la deuda externa y para diciembre de 1991 esta alcanzó un saldo de 12802 millones de dólares, equivalente a 111.1\% del PIB. ${ }^{22}$ A pesar de las dos negociaciones concretadas durante la década perdida, mientras en 1981 el saldo inicial de la deuda fue de 4651.7 millones de dólares, 1990 terminó con un saldo final de 12222 millones, es decir, casi tres veces más alto (cuadro 9).

\section{CONCLUSIONES}

Como en toda América Latina, en Ecuador la década perdida fue un largo periodo de crisis en la que retrocedieron el crecimiento y la inversión (cuadro 10). Como se ha visto, esa década fue mucho más que de estancamiento económico. Fue el inicio de una nueva etapa de la historia económica ecuatoriana, un largo momento de auténtico cambio de época y de

\footnotetext{
${ }^{22}$ Acosta (28 de diciembre de 2008) sostiene que la estrategia del equipo económico del presidente Borja fue costosa e inútil.
} 


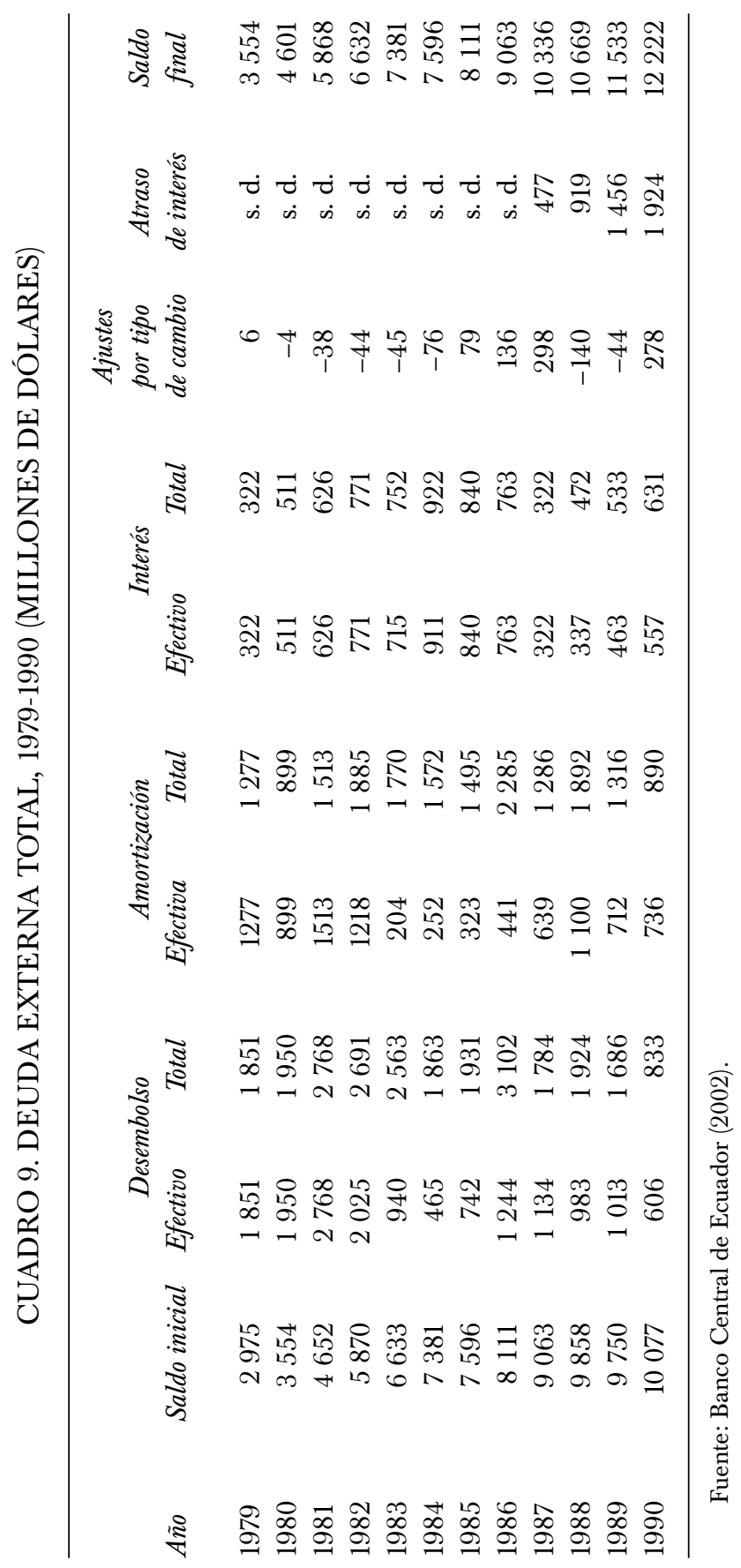


transición desde el paradigma de la ISI hacia la modernización neoconservadora de los equilibrios macroeconómicos, la reducción del Estado, los mercados desregulados y la apertura comercial.

Con una economía anquilosada por la enfermedad holandesa, en un horizonte de términos de intercambio negativos, proteccionismo en los mercados de las exportaciones latinoamericanas y un pesado servicio de la deuda externa, este cambio de época se fraguó con la modificación de las herramientas y objetivos de la política económica, según las prescripciones del enfoque monetario de la balanza de pagos. Esta modificación requirió transformar la estructura institucional en la que se gestaron las políticas de ajuste. Por un lado, el eje institucional de la política pública se trasladó desde la Junta Nacional de Planificación hacia la Junta Monetaria del BCE y, por otro, el BCE se convirtió en el interlocutor idóneo del FMI, el garante internacional de los acreedores externos y monitor de las mutaciones políticas e institucionales requeridas por la nueva época.

Bajo la lógica y los supuestos del enfoque monetario de la balanza de pagos, los objetivos de largo plazo de la política de industrialización por sustitución de importaciones fueron suplantados por otro objetivo, de corto plazo: el control del déficit fiscal. La disciplina fiscal es, según el enfoque monetario de la balanza de pagos, indispensable para evitar la monetización de los desequilibrios provocados por el excesivo gasto público que acelera la inflación. Al mismo tiempo, al evitar el déficit fiscal, el acopio de recursos para atender los vencimientos de la deuda externa puede ser mayor, algo que era indispensable para tratar de satisfacer el servicio de esos pasivos.

Los tres gobiernos que se sucedieron entre 1981 y 1992 tuvieron diferentes filiaciones políticas. Sin embargo, todos ellos tuvieron el mismo objetivo fiscal, lo que se confirma al examinar el nivel decreciente del consumo final de las administraciones públicas y de la inversión pública (formación bruta de capital fijo de las administraciones públicas) a lo largo de la década (cuadro 10).

La modificación más significativa de la política económica en la constitución de la nueva época fue el cambio de la política cambiaria. Por más de dos décadas, hasta marzo de 1982, el dólar estadunidense se mantuvo constante en 25 sucres. Pero desde esa fecha la paridad cambiaria fue modificada mediante un variado conjunto de expedientes: cambios no anticipados o planificados de la paridad nominal, cambios de listas de importación, anticipos, retenciones y otros mecanismos administrativos, de forma que en el mercado libre, entre 1980 y 1991, el sucre se devaluó $3857 \%$. El primer efecto de la devaluación de marzo de 1982 fue encarecer en sucres el valor de deudas externas contratadas en dólares. En conjunción con el incremento de las tasas de interés internacionales, el default mexicano y la 


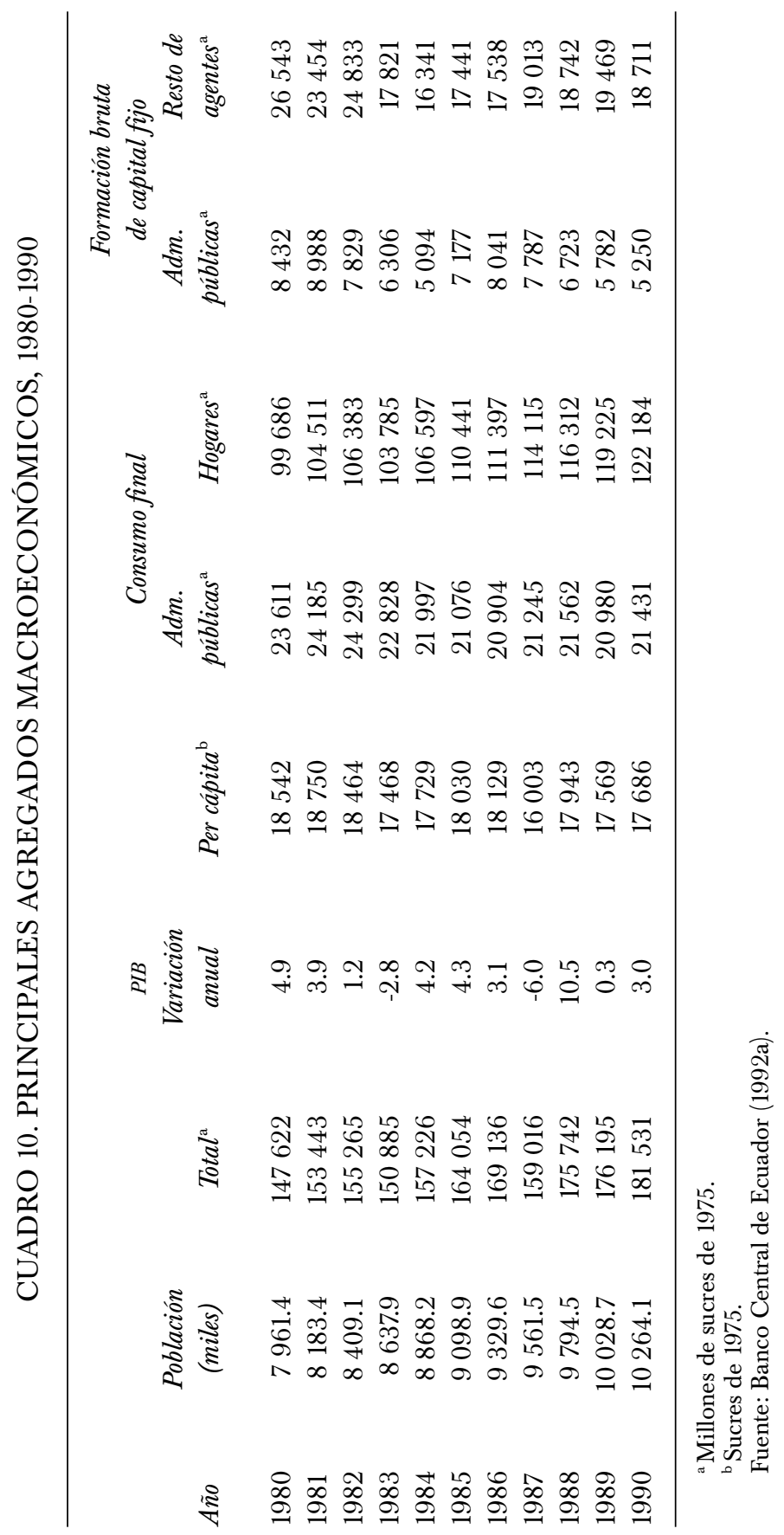


reducción de la demanda de los productos de exportación ecuatorianos, la devaluación contribuyó a que esas deudas fuesen imposibles de pagar.

La devaluación también permitió reducir los costos de producción de exportaciones primarias poco atendidas por las políticas públicas durante la década del auge petrolero, trasladar el peso del ajuste a los perceptores de salarios e incrementar las ganancias en sucres de los exportadores. La recuperación de las exportaciones primarias sirvió para que los grupos económicos más tradicionales recuperaran su poder, focalizándolo en la Junta Monetaria del BCE, que se convirtió en el eje de las políticas de reforma.

El PIB creció a una tasa anual real promedio de $2.4 \%$, mientras que la población lo hizo a 2.6\%. Al mismo tiempo, los saldos de la deuda externa total (pública y privada) crecieron a una tasa promedio de $12.1 \%$ anual. La deuda externa fue refinanciada en dos ocasiones (1983 y 1985), pese a lo cual el saldo final de 1990 terminó siendo tres y media veces superior al saldo inicial de 1980, y equivalente a más de 100\% del PIB de ese año (véase cuadro 9).

La deuda externa pública también se incrementó debido a una opaca operación financiera conocida como sucretización. Entre 1983 y 1988 el BCE asumió 66110 millones de sucres (1 476 millones de dólares) de deuda externa privada, y fue obligado a asumir el riesgo cambiario de esa operación, lo que le habría costado otros 600000 millones de sucres. Esta forma de socializar las pérdidas privadas muestra la manera como los grupos de poder se sirvieron del ajuste para evitar el juego del mercado y concentrar su riqueza, incluso contrariando las recomendaciones del FMI.

El FMI fue tanto un aliado como un enemigo: aliado para erosionar al Estado intervencionista heredado de la década previa y para desregular mercados en beneficio de esos grupos, y enemigo cuando las disputas distributivas entre esos grupos y los acreedores externos se tornaban irreconciliables.

Los años ochenta se recuerdan como un largo periodo de sucesivas crisis fiscales y de balanza de pagos. En realidad fueron los años del colapso final de los intentos de desarrollo industrial en la mayoría de países medianos y pequeños de la periferia del capitalismo. Mientras la ISI parecía desvanecerse inexorablemente, emergía triunfante la ideología neoconservadora plasmada en 1989 en el Consenso de Washington. 


\section{ANEXO \\ RECUADRO 1. ENFOQUE MONETARIO DE LA BALANZA DE PAGOS (EMBP)}

Entre las décadas de los años cincuenta y sesenta del siglo pasado, en la Universidad de Chicago y en el FMI se estudió la secuencia de eventos económicos que conducen a las crisis de balanza de pagos. Para 1976 J. A. Frenkel y H. G. Johnson editaron para Allen \& Unwin el libro The monetary approach to the balance of payments con ensayos que se impusieron como referentes para tratar esas crisis.

El ЕмBP es heredero de la antigua idea clásica que propone que el incremento del stock de dinero se traduce en incremento del gasto, que produce déficit en la balanza de pagos. Si el tipo de cambio se mantiene fijo, la oferta monetaria se torna endógena, como a su tiempo lo propusieron David Hume y John S. Mill. En esta situación el ajuste se produce mediante arbitrajes propiciados por la ley de un solo precio, según lo habían estudiado David Ricardo (1809) y Knut Wicksell (1919). El EMBP perdió credibilidad con el colapso del sistema monetario internacional de 1931, pero 30 años más tarde Robert Mundell propuso aplicar políticas monetaria y fiscal para simultáneamente lograr pleno empleo y equilibrio externo.

Antes de los años ochenta, en América Latina y en el Norte prevalecieron los enfoques de absorción, que destacan las condiciones de la demanda, dada una oferta. Pero con la crisis de la deuda externa se extendió el EMBP como herramienta teórica para aplicar los ajustes macroeconómicos promovidos por el FMI (Massad, 1980). La versión más empleada del EMBP fue desarrollada a principios de los años setenta por Harry Johnson, quien elaboró su propuesta a manera de rechazo a la economía keynesiana (Polak, 2002).

El ЕмвР afirma que los desequilibrios externos son fenómenos monetarios. Dado que en el balance del banco central el dinero de alto poder $(H)$ es igual a las reservas internacionales $(F)$ más el crédito interno $(D)$, se tiene que la oferta monetaria $(M)$ está determinada por un múltiplo de $H$, tal que

$$
M=h H=h(F+D)
$$

donde $h$ representa el multiplicador monetario. Tomando primeras diferencias y reordenando se obtiene

$$
\Delta F=\Delta M-\Delta D
$$

donde $\Delta F$ representa la variación de las reservas internacionales, $\Delta D$ la expansión del crédito interno y $\Delta M$ el crecimiento de la demanda flujo de dinero. Si se asume estable el tipo de cambio, la variación de las reservas internacionales será igual al saldo de la cuenta corriente $(B)$ más el saldo de la cuenta de capitales $(K)$ de la balanza de pagos, 


$$
\Delta \mathrm{F}=\mathrm{B}+\mathrm{K}
$$

Entonces, si ambas cuentas de la balanza de pagos fueran deficitarias, el país perderá reservas internacionales. Y, si se igualan las dos ecuaciones anteriores,

$$
\Delta M-\Delta D=B+K
$$

que evidencia que una expansión del crédito interno mayor que el crecimiento de la demanda flujo de dinero necesariamente implica déficit en la cuenta corriente, en la cuenta de capitales o en ambas.

En consecuencia, el control del déficit de la balanza de pagos requiere restringir la expansión del crédito interno, que sería la causa fundamental del desequilibrio externo. Como el mayor incentivo para la expansión del crédito interno es el déficit fiscal, es ineludible evitarlo, o al menos lograr superávit primarios en las cuentas del gobierno.

\section{LISTA DE REFERENCIAS}

Acosta, A. (1994). La deuda eterna. Una historia de la deuda externa ecuatoriana. Quito: Libresa.

Acosta, A. (28 de diciembre, 2008). El drama de los Bonos Brady. Y una renuncia unilateral a la prescripción de la deuda. Rebelión. Recuperado de http://www.rebelion. org/noticia.php?id=78073

Banco Central de Ecuador (1983). Memoria anual 1982. Quito: Autor.

Banco Central de Ecuador (1989-1990). Boletín anuario, núm. 12. Quito: Autor.

Banco Central De ECUADOR (1990a). Cartas de intención suscritas por el gobierno del Ecuador con el Fondo Monetario Internacional. Quito: Autor.

Banco Central de Ecuador (1990b). Memoria anual 1989. Quito: Autor.

Banco Central de Ecuador (1992a). Cuentas nacionales. Publicación núm. 15 [19661991]. Quito: Autor.

Banco Central de Ecuador (1992b). Boletín anuario, núm. 14. Quito: Autor.

BANCO CENTRAL DE ECUADOR (2002). Setenta y cinco años de información estadística 19272002. Quito: Dirección General de Estudios del Banco Central del Ecuador.

Bayas, S. y Somensatto, E. (1994). Programa de sucretización ecuatoriano: historia de los efectos monetarios de la conversión de la deuda externa del sector privado. Cuestiones Económicas, 23.

Bértola, L. y Ocampo, J. A. (2012). El desarrollo económico de América Latina desde la independencia. Buenos Aires: Fondo de Cultura Económica.

Bucaram, R. (1983). La situación petrolera en el Ecuador. En E. Ayala (coord.), Libro del Sesquicentenario III, Economía Ecuador: 1830-1980. Quito: Corporación Editora Nacional. 
Corden, M. W. y Neary, J. P. (1982). Booming sector and de-industrialization in a small open economy. The Economic Journal, 92(368), 825-848.

Emanuel, C. J. (1986). Deuda externa y políticas de ajuste [conferencia]. Seminario Crisis Económica y Perspectivas de Desarrollo en América Latina. Quito: BCE.

Fierro, L. (1991). Los grupos financieros en el Ecuador. La concentración del capital bancario en el Ecuador. Quito: CEDEP.

Harvey, D. (2004). La condición de la posmodernidad. Investigación sobre los orígenes del cambio cultural. Buenos Aires: Amorrortu Editores.

Jácome, L., Larrea, C. y Vos, R. (1998). Políticas macroeconómicas, distribución y pobreza en el Ecuador. Quito: Ediciones Mundiprensa. Recuperado de http://biblioteca. bce.ec/cgi-bin/koha/opac-detail.pl?biblionumber $=7330$

LARrEA, C. (2006). Hacia una historia ecológica del Ecuador. Quito: Ecociencia/Corporación Editora Nacional/Universidad Andina Simón Bolívar.

Massad, C. (1980). El enfoque monetario de la balanza de pagos y el enfoque de absorción: ¿̇resultados contradictorios? Estudios de Economía, 7(1).

Naranjo, M. (2006). Auge petrolero y enfermedad holandesa en el Ecuador. En G. Fontaine (ed.), Petróleo y desarrollo sostenible en Ecuador 3. Las ganancias y las pérdidas. Quito: Facultad Latinoamericana de Ciencias Sociales-Ildis/Fes-Petrobras.

NARAnjo, M. (2007). Los años 70: auge petrolero y enfermedad holandesa. En Encuentro de Historia Económica: La década de los setenta: auge petrolero y endeudamiento externo (pp. 67-109). Quito: BCE.

OCAMPO, J. A. (2008). Los paradigmas del desarrollo en la historia latinoamericana. En O. Altimir, E. V. Iglesias y J. L. Machinea (eds.), Hacia la revisión de los paradigmas del desarrollo en América Latina. Santiago de Chile: CEPAL/Secretaría General Iberoamericana.

POLAK, J. (2002). Los dos enfoques de la balanza de pagos: el keynesiano y el johnsoniano. Monetaria, 25(1).

RodDick, J. (1990). El negocio de la deuda externa. América Latina y los bancos internacionales. Bogotá: El Áncora Editores.

THORP, R (1998). Progreso, pobreza y exclusión. Una historia de América Latina en el siglo XX. Washington: Banco Interamericano de Desarrollo/Unión Europea.

Thoumi, F. y Grinde, M. (1992). La política de la economía del ajuste: la actual experiencia ecuatoriana. Quito: Facultad Latinoamericana de Ciencias Sociales.

TORRE, A. DE LA (1987). Macroeconomic aspects of a petroleum boom: Ecuador, 1972-1980, (tesis doctoral). Notre Dame, Indiana, University of Notre Dame.

VAREA, M. (1993). Una aproximación teórico-empírica al sobreendeudamiento ecuatoriano. En A. Acosta, J. Gallardo, H. Ramos, M. Varea, S. Pérez y S. Nieto, Deuda externa y renegociación. Quito: Fondad/Grupo de Trabajo sobre Deuda Externa y Desarrollo.

Wunder, S. (2004). Petróleo, macroeconomía y bosques. En F. Falconí y J. Oleas (comps.), Economía ecuatoriana. Quito: Facultad Latinoamericana de Ciencias Sociales. 


\section{OTRAS FUENTES}

Banco Central de Ecuador (2007). 80 años de información estadística (Series Estadísticas Históricas). Recuperado de http://www.bce.fin.ec/frame.php?CNT =ARB0000006

Corden, M. W. (febrero, 2012). The Dutch disease in Australia. Policy options for a three-speed economy. Australian Economic Review, 45(3), 290-304.

Harvey, D. (2007). Breve historia del neoliberalismo (vol. 49). Madrid: Akal.

Mills, N. D. (1984). Crisis, conflicto y consenso. Ecuador: 1979-1984. Quito: Corporación Editora Nacional. 